Research Article

\title{
Calculating TIN-Based 3D Sight Distance and Its Evaluation on Drivers Free-Flow Speed
}

\author{
Ali Sahaf (D, Ali Abdoli, and Abolfazl Mohamadzadeh Moghaddam \\ Department of Civil Engineering, Ferdowsi University of Mashhad, Mashhad, Iran \\ Correspondence should be addressed to Ali Sahaf; asahaf@um.ac.ir
}

Received 31 May 2021; Revised 14 June 2021; Accepted 10 July 2021; Published 4 August 2021

Academic Editor: S. Mahdi S. Kolbadi

Copyright (c) 2021 Ali Sahaf et al. This is an open access article distributed under the Creative Commons Attribution License, which permits unrestricted use, distribution, and reproduction in any medium, provided the original work is properly cited.

\begin{abstract}
Sight distance during driving may be limited by side factors such as mountain slopes or trees and buildings in horizontal curves and by the dome of the arc in vertical curves, and the night vision also can be limited in the sag vertical curves by the vehicle's light. Analyzing driver's sight distance in the road is very important for traffic safety. In this regard, in order to help the designer, the current rules and guidelines propose the two-dimensional analysis model for the sight distance. In this analysis, the sight distance is calculated separately in the combination of horizontal and vertical curves, and the smallest amount is considered as the sight distance. While, after constructing and operating the road, drivers control their vehicle according to the conditions in their 3D space. Nowadays, given the remarkable advances in computer science, there are many possibilities for 3D modeling of the route. In this research, the goal is to calculate the three-dimensional stopping sight distance at each spatial point by computer modeling the existing roads. The speed of various drivers with conventional riding vehicles under free traffic conditions was obtained by a GPS device. The results showed that, in places such as curves, given the provision of sufficient stopping sight distance, driver's free-flow speed reduces. Thus, another factor affecting the speed of the drivers is the curvature change rate. Finally, using nonlinear regression modeling a logical relationship was determined and extracted between the three factors of driver's free-flow speed, $3 \mathrm{D}$ stopping sight distance, and curvature change rate of the path.
\end{abstract}

\section{Introduction}

The line of sight in the driving lines in horizontal curves may be blocked by side factors such as the trees and buildings or the hillside in cases where there is a need to cut the mountain. In the convex vertical curves, the line of sight may be covered by the very arc. Also, night vision in concave vertical curves may be limited by vehicles' light. The calculation of the sight distance in the geometric design of the road is usually based on regulations and two-dimensional space. While in practice (after construction and operation of the road), drivers control their vehicles under conditions affected by gradient, altitude, longitude, and latitude, in other words, based on the conditions in the three-dimensional space. The difference between design conditions and operating conditions is seen in parts of the road with special geometric conditions, including the combination of horizontal curves and vertical curves [1].
The stopping sight distance in the two-dimensional mode is plotted on the plan and recorded at sequential intervals. The designer chooses the minimum distance recorded in the plan or profile [2]. Therefore, the results are conservative and do not express the exact extent of the available sight distance [3].

Nowadays, given the remarkable advances in computer science and programming, there are many possibilities for 3D modeling of the route [4]. Therefore, the calculation of the sight distance should be based on existing facts and new scientific achievements. On the contrary, the spatial information system has been used in various transport areas since 1980 [5]. Topographic profiles were used throughout the transverse sections to evaluate the sight distance. This process was very time consuming and depended on the precision and details of the topographic map. An example of an old topographic map and how to calculate the sight distance is visible in Figure 1. 


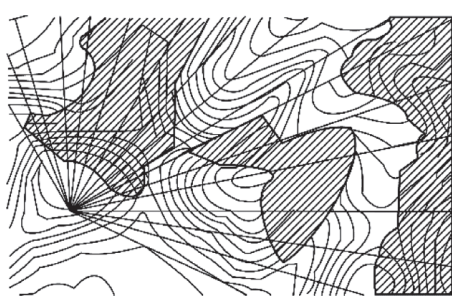

(a)

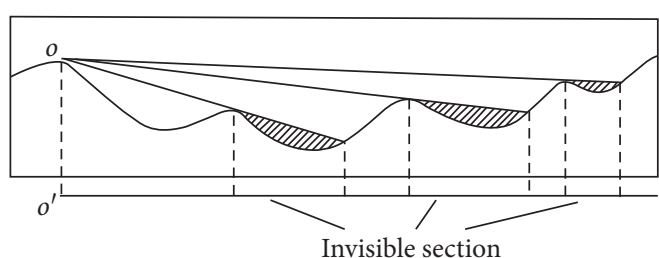

(b)

Figure 1: Manual evaluation of available sight distance.

Today, the analysis of the sight distance between two points of the Earth's surface is used by most users of the spatial information system. Most spatial information system software have the ability to calculate visible areas from the observer's location. This ability is used in strategic military areas, urban design, telecommunications operators, and roads. The concept of the sight distance indicates whether the target point on the ground is visible from the viewer's location [6]. On the contrary, sight distance analysis is integrated with other traffic safety analysis, such as design consistency analysis, which is related to design and performance speed [7]. Hence, more and more complete models can be created and costs can be cut down [5]. Also, one of the factors influencing the free-flow speed of drivers is the sight distance ahead of the driver. The main objective of this research is to provide a suitable solution and model for calculating the three-dimensional stopping sight distance of existing two-way suburban roads. On the contrary, it is assumed that there is a meaningful relationship between the stopping sight distance and the driver's free-flow speed; hence, the purpose is to create a logical relationship between the available 3D stopping sight distance and the driver's freeflow speed at any point in the route. Also, the various types of sight distances (stopping and overtaking) can be calculated with the stated methods.

\section{Literature Review}

Many researchers have worked on calculating the sight distance in three dimensions. Among them, Hassan et al. [8] studied the effects of route design with regard to the threedimensional sight distance, compared the results in twodimensional mode, and concluded that 3D design standards in geometric design of the route should be expanded and used. Khatak and Shamayleh [9], using the topographic data obtained from the flight of a LIDAR-equipped aircraft, on a cross section of a two-way route, identified ten districts with problems in overtaking and stopping sight distance in the GIS environment, and through field reviewing, all the problems were confirmed. Kim and Lovell [10] proposed a new 3D vision model that simultaneously took into consideration the horizontally and vertically factors, as well as other necessary factors such as road shoulder and external barriers. Chou et al. [11] used the finite element method to calculate the stopping sight distance in a combination of vertical-convex and horizontal curves on a two-way road. The results indicated that the ratio between the curved vertical arc parameter $(\mathrm{kv})$ and the horizontal $\operatorname{arc}$ radius $(R)$ influenced the stopping sight distance. Castro et al. [5] compared the road sight distance analysis using other spatial information tools and other software, and the results of the spatial information system tool were confirmed.

Fotis et al. [12], at the University of Athens, managed to design a software called $\mathrm{H} 11$ and presented it in an article as a model for calculating sight distances and three-dimensional evaluation of the route in separated and not separated routes. In another article, entitled "sight distance," in order to analyze road safety using the spatial information system, Barbell et al. [13] introduced a tool to be installed in the ArcGIS software environment, which can be used to calculate three-dimensional sight distances. Similarly, Castro et al. [14] introduced an enhancer tool for sight distance calculation for ArcGis software in the form of an article. Also, according to the calculation of the available sight distance required from any point, a graphical comparison possibility is provided to the user. In another article, Castro et al. [15] succeeded in providing a model for measuring hidden vision parameters. In this innovative method, they used ground reference images to measure distances in the road. The advantages of this method are that there is a very low error rate in the calculations, as well as the lack of need for ground models for calculations.

\section{Materials and Methods}

3.1. Speed Prediction Models. As it is clear that, by reviewing the previous works, the importance of calculating the sight distance in three dimensions has been proven. Therefore, studies on speed prediction are discussed below. So far, various studies have been carried out to present the drivers' speed prediction model, which will be discussed further. Dilling [16] introduced the first performance speed prediction model in Germany. According to his model, the factors affecting the speed of the drivers were expressed in terms of average speed in curve, curve radius, path's width, and path curvature change rate. In the same year, Laam [17] also presented a model for predicting the performance speed by taking 200 speed data in a road with vertical arcs of different slopes, based on the special parameter defined by the author for the various widths of the road. Koeppel and Fahrgeschwindigkeiten [18] developed two models for estimating the average instantaneous speed based on the parameters of the route curvature change rate, the width of the route, and the average sight distance of 400 meters near 
the given section. Other models were obtained by Laam et al. [19] for different latitudes of the routes, based on the arc angle and the speed allowed in the arc, using information from 261 districts of the state of New York.

Laam et al. [20] gathered different curves' information of roads with shoulder and daily traffic of between 400 and 5000 vehicles per hour for various vehicles including cars, vans, pick-ups, and trucks and presented a model based on arc angle, route width, width of the shoulder, and daily traffic volumes. In this model, the width of the route, shoulder width, and annual traffic amount justify only 5.5\% of speed changes. Moral and Talarico [21] and, in another article in the same year, Islam and Seneviratne [22] presented their speed estimation models based on the angle of curve. Krammes et al. [23] examined the performance speed of different curves and the straight entry paths of these curves in several ways in three different regions of the United States and presented their model based on the parameters of arc angle, curve length, angle of arc deviation, and $85 \%$ calculated speed in the straight entry path of the arc. Voigt and Krammes [24] developed a series of models to predict $85 \%$ drivers' performance speed in the middle of the arc, based on speed information and geometry of curves, from 138 simple circular arcs and 78 straight paths to curves, in suburban two-ways roads of five different areas, and for each region measured the speed of at least 100 drivers at the A service level condition. Their model is based on the parameters of the rate on height, arch length, and angle of arc deviation. Lipold [25] and Passetti and Fambro [26] presented their proposed relationship based on the curve radius variable.

McFadden and Elefteriadou [27] extracted the information they needed for modeling the 85 percent maximum speed drop in arcs from 21 arcs and based their model on the 85 percent speed variables in 200 meters to the beginning of arc, arc radius, and the length of the straight entry path to the curve. In another study, Fitzpatrick et al. [28] proposed models for the combination of horizontal and horizontal curves. Information were gathered at Service Level A which was from 176 regions of 6 states, and the results were written in a table for different slopes. Jessen et al. [29] modeled speeds of $50 \%, 85 \%$, and $95 \%$, respectively, in the service level, conditions for cars in 70 vertical arcs of the region. In the end, the authors stated that, in the vertical arcs, the entry slope has an inverse impact on the speed at the points with the least visibility, and by increasing the slope, the speed decreases. Nei and Hassan [30] studied the speed of drivers in two-way suburban roads. They modeled a total of 10 horizontal arcs, on average, for each of the 25 speeds were observed under Service Level A conditions, and the performance speed model depends on a large extent on the route geometry. Therefore, speed in straight routes depends on the roads' length and on arcs depends on the rate of change of curvature of arc and radius of the curve. Cafiso et al. [31] used data extraction of 80 cross sections of suburban twoway roads to provide a model for predicting speed in straight routes and curves based on variables of curvature change rate, width, and lengths of the route.
3.2. Determining the 3D Sight Distance Using GIS Device. Today, there are numerous software tools available for working with spatial data, including advanced software such as ArcGIS, developed by ESRI. ArcGis software allows the creation of a complete system of spatial information. One of the most powerful tools in this set is calculating the sight distance simultaneously in three dimensions. To calculate the sight distance between two points, the software initially analyzes the natural land along the line of sight and then compares the observer-target elevation vector and the height of the ground along the sight line. If the natural land is plotted above the line of sight along the line of sight so that it disconnects the target's observation, then the target is considered invisible. On the contrary, the target can be seen if the natural land is not above the line of sight [5].

First, before calculating the sight distance, the actual model of the ground and the path should be prepared. These models can be in the form of a raster or a cector. Vector and raster models have advantages and disadvantages over each other. In fact, it can be said that the relationships between the segments forming a raster data (pixels) are much simpler than the topological relationships between the effects in the vector file. This also complicates the processing performed on a vector file. The differences between the raster and vector model are shown in Figure 2. One of the basic vector models is the triangular irregular network (TIN). TIN has been used for many years in the Geospatial Information System to build a ubiquitous Earth model. This method was first introduced in 1978 by Piquer et al. There are various triangulation methods among which Delonic triangulation is more useful in building a 3D model of land's surface in GIS. In the Delonic technique, the heights are located at the vertices of the triangles and the edges connect the points.

Because triangulation depends on the number of sample points, so if the number of points is large, the TIN will have larger magnitudes because more triangles are made. Placing the surface effects in the form of a point, line, or surface produces a TIN in a way that gives a better display of ground phenomena. Therefore, in this study, we try to construct and use these precise and prominent models. On the contrary, the TIN model is very efficient and accurate to calculate the 3D sight distance in ArcMap (of the ArcGIS subsets). Steps to determine the 3D sight distance in the ArcMap environment are, respectively, choosing the TIN model for calculating the $3 \mathrm{D}$ sight distance, pressing the button to make the sight distance line in the software in the 3D analysis section, setting the viewer's height and the target's, clicking on the viewer's location, and clicking on the target's location. As shown in Figure 3, the black spot is the viewer, the blue spot is the obstruction, the red spot is the target, the green lines are the visible areas, and the red lines are the invisible regions.

Here, after modeling the route, from each arbitrary point, all lines of the sight distance are plotted, and in the end, the smallest sight distance obtained on the track is considered as the actual 3D sight distance. 


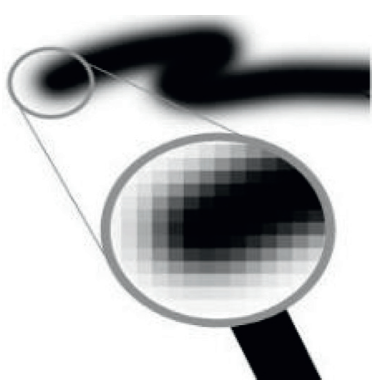

(a)

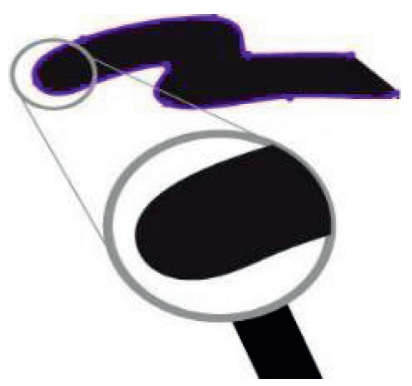

(b)

Figure 2: Comparison between vector and pixel image. (a) Raster. (b) Vector.

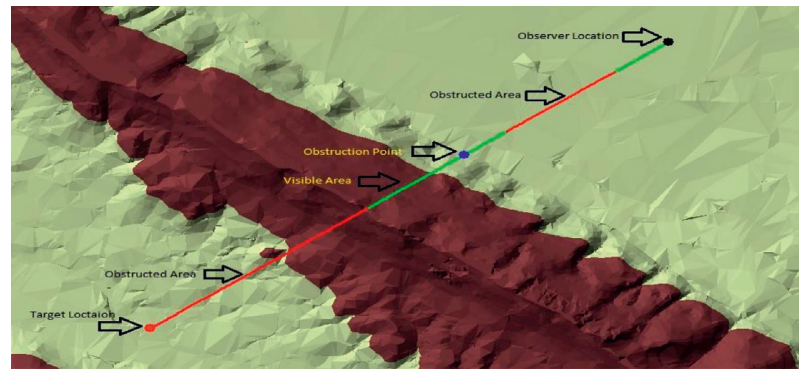

Figure 3: 3D sight distance calculation by using TIN.

3.3. Data Collection. As previously stated, in this paper, it is attempted to calculate the existing 3D stopping sight distance by computer modeling of the three existing paths, and then, by capturing the speeds of the drivers, we obtained a logical relationship between the available $3 \mathrm{D}$ stopping SIGHT distance and drivers' free-flow speed. Three mountainous highway routes were chosen for this purpose. Selected routes are the main axes of the northeast of Khuzestan province in Iran which is considered as the connection bridge between the south and the north of the country. By obtaining the TIN models, the remaining route data, including lines for detecting routes and their projection on these models, are performed to find the desired routes. In Figures 4 and 5, an example of the location of the route on the TIN model is shown on the route from Baghmalek to Izeh. At this stage, having all the information and the use of the line-of-sight tool, the calculation of the two-way $3 \mathrm{D}$ stopping sight distance is performed on all three routes (Figure 6). This tool is capable of detecting the visibility between the two points (Figure 7). For this purpose, based on the AASHTO standards, the height of the observer's eyes is as high as 1.08 and the objective or obstacle's height is equal to 0.6 .

After calculating stopping sight distances on existing routes using field surveys and GPS, speed was calculated for different drivers with different specifications under Service Level A conditions. On the contrary, after removing the three-dimensional distance information and free speed of drivers, in some parts of the route, especially in the arches, we witness that, with the provision of enough sight distance, free speed considerably reduces. The reason for this event is the rate of change in the curvature of the arc. To calculate the

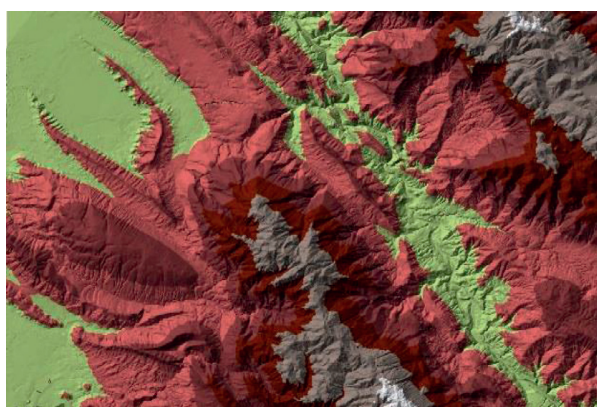

Figure 4: Izeh to Dehdez paths TIN.

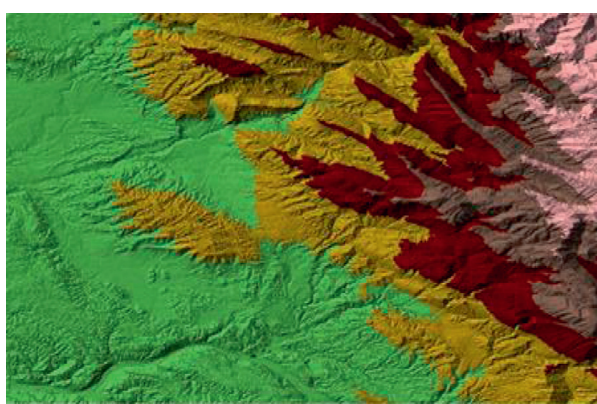

Figure 5: Seydoun to Baghmalek paths TIN.

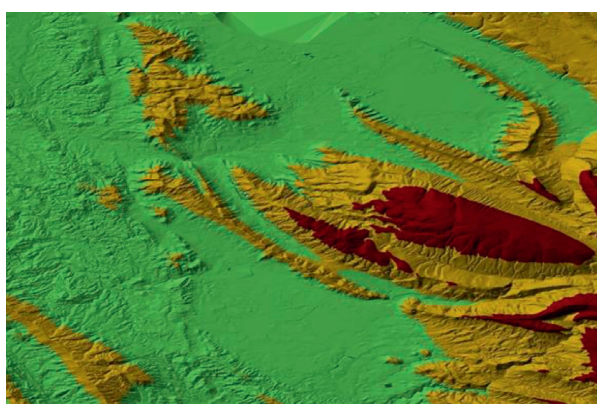

FIgURE 6: Baghmalek to Izeh paths TIN.

curvature variation rate of the arc, firstly, the calculated angles, the points in the curve of the path have a value, and the points that are in the path tangent to the curvature change rate are zero. Thus, for all the paths available, this factor was evaluated as well. 


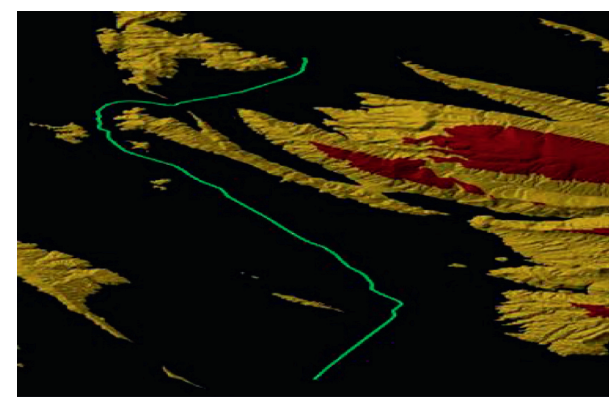

FIgURE 7: Location of road on TIN.

\section{Results and Discussion}

Because the $3 \mathrm{D}$ stopping sight distance is variable along the route, it is possible to plot a comparison diagram between the $3 \mathrm{D}$ existing sight distance and the minimum regulated stopping sight distance on the route to determine the areas with stopping sight distance less than the minimum regulations that are also considered as the accidental points, as shown in Figure 8.

Regarding the main subject of this research, now the issue is that whether the measured speeds are related to the reduction or increase in the $3 \mathrm{D}$ stopping sight distance at each point. Based on this, we first study the existence or absence of an implicit relationship on the graph by charting and comparing the recorded speeds and the $3 \mathrm{D}$ stopping sight distance at different points of the route. For example, in Figure 9, the distance between the 3D stopping sight distance and the free-flow speed of one of the drivers is given. As can be seen in Figure 9, the speed of the driver increases and decreases with the increase and reduction of the actual stopping sight distance. This is very evident in the curves where the distance between the stopping sight distances is sharply reduced.

Therefore, it can be stated that, in the high mountain routes where the number of curve is high, the relationship between the stopping sight distance and the speed is greatly increased. On the contrary, given the information collected in the areas of the routes with curves, despite the appropriate stopping sight distance in some of these curves, a decline in the speed of the drivers is visible. The deceleration factor in

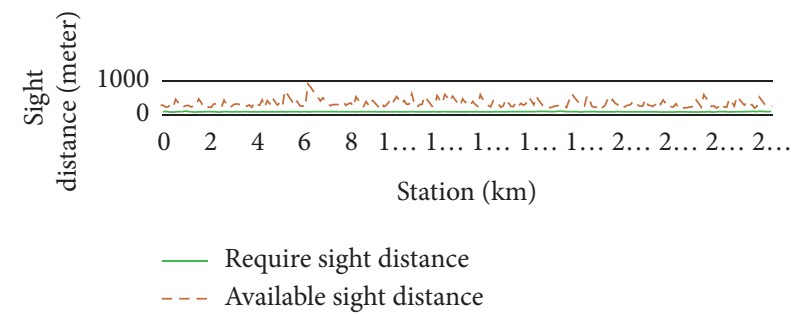

FIgURE 8: Comparison between required and available 3D sight distance (Baghmalek to Seydoun route).

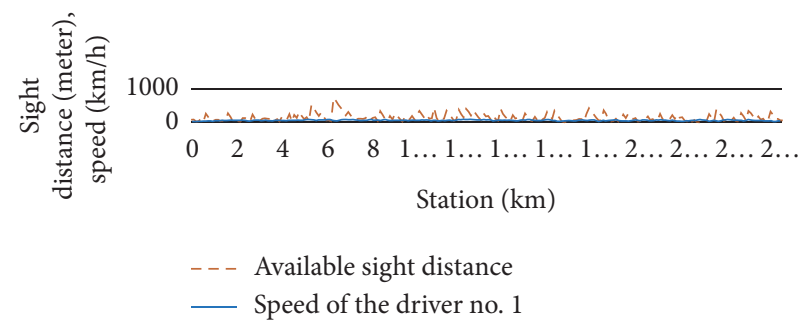

FIgURE 9: Comparison between available 3D sight distance and free-flow speed of the first driver (Baghmalek to Seydoun route).

these areas is the curvature change rate (CCR). Because, due to the sufficient sight distance, the driver instinctively reduces the speed in curves. In addition, the free-flow speed increase proportional to the increase in the stopping sight distance is limited by the various factors, including the strength and tension of the vehicle. Therefore, using segmented regression models, the goal is to provide a model for predicting the free-flow speed of drivers at any point in the route. As it is clear from the relations obtained, the 3D stopping sight distance factor and free-flow speed are directly related, and an increase in stopping sight distance increases the driver's free-flow speed. On the contrary, as stated earlier, the route's curvature change rate is one of the factors affecting driver speed reduction. Also, for the routes under study, speeds over limit are recorded, especially in areas where the curvature change rate is negligible or zero, and there is a large stopping sight distance:

$$
S_{f f}=\left[\begin{array}{cc}
7821.86 \mathrm{ASD}^{0.002}-(7842)+\exp (-0.002535 * \mathrm{CCR}+1.919), & 9 \leq \mathrm{ASD} \leq 1137.5, \\
97.5, & \mathrm{ASD}>1137.5,
\end{array}\right]
$$

where $S_{f f}$ is free flow speed $(\mathrm{km} / \mathrm{h})$, ASD is available $3 \mathrm{D}$ sight distance (meter), and CCR is curvature change rate (Grad). Figure 10 shows the rate of variation of free-flow speed according to changes in the $3 \mathrm{D}$ stopping sight distance and the curvature change rate.

As shown in Figure 10, with increase in the free-flow speed, 3D stopping sight distance increases. As the rate of curvature change increases, the free-flow speed of drivers decreases. With 3D stopping sight distance 1137.5 meters, the free-flow speed of drivers has been minimized, and then, the free wheel speed is 97.5 for most drivers. Moreover, the lowest 3D stopping sight distance along these routes was 9 meters. Thus, the lowest visibility same was considered. Moreover, given the lack of turns and arches in these mountainous trails, sight distance increases in these areas. 


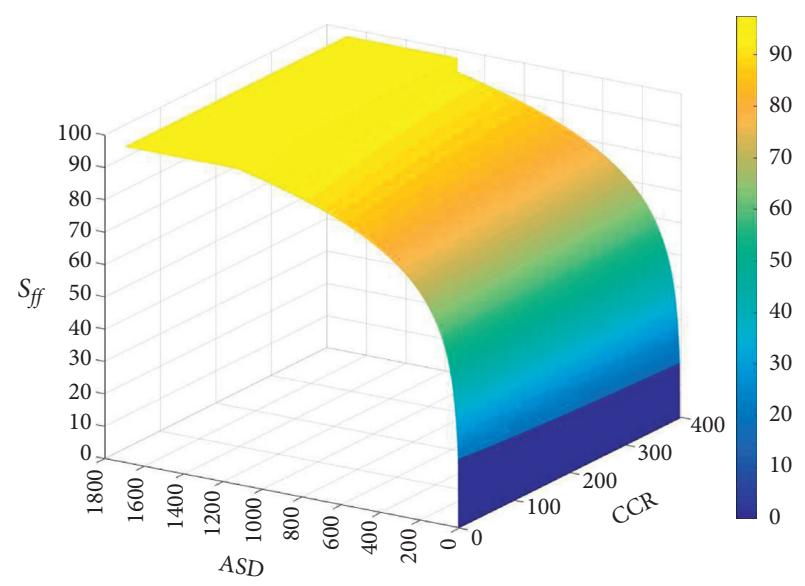

FIgURE 10: The rate of variation of free-flow speed according to changes in the $3 \mathrm{D}$ stopping sight distance and the curvature change rate.

\section{Conclusion}

One of the drawbacks to designing a route is the lack of a precise method for calculating the driver's sight distance. To design the route, the designer calculates the sight distance based on the two-dimensional method, while in reality, these values vary compared to the actual value. This factor can put more cost on the plan. On the contrary, the ability to use 3D modeling of the route design as well as $3 \mathrm{D}$ topographic simulation of the area can be very effective and useful. As stated in the previous sections, the main purpose of this research is to provide a method for 3D modeling of the route and the determination of the available sight distance by new computer methods. The 3D stopping sight distance was taken in different parts of these paths. In the following, given the significant impact of the driver's stopping sight distance on free-flow speed, a logical model is proposed for calculating the free-flow speed at each point of the route. In this study, several useful results were obtained that could significantly help design the route. As stated, using a 3D topographic modeling of the route, a better and more accurate view of the area can be achieved to determine the best route. On the contrary, given the old or absent information about most of the available routes, one can use the proposed methods to accurately model existing ones. Also, using the obtained models, overtake and stopping sight distances are quite measurable. It is clear that if the sight distance ahead of the driver is available, the cost of design and implementation of the road will be reduced, especially in areas where there is no possibility to calculate sight distance, and the maximum distance is taken into account which is far from the actual distance.

Other achievements of this research are the possibility of increasing the speed and accuracy in calculating the sight distance at any desired point in the design and modeling processes. In the following, considering the ability to calculate the sight distance at any point and to compare it with the minimum level in the regulations (overtake and stopping sight distance), the areas lacking sufficient sight distance are specified and the route is modified for safety. The last output of this study is the ability to estimate the free-flow speed of drivers according to the stopping sight distance available. Therefore, the location of susceptible areas of danger will be possible due to the increased control speed and reducing vulnerability of those areas. This study has been tried to provide some help in designing the route. Now that computer tools are available, it is best to compensate the lack of information about the existing routes. On the contrary, due to the ability to model the routes based on the proposed methods of this research, one can carry out useful studies on road safety and decrease the number of deaths and injuries caused by accidents.

\section{Data Availability}

The data used to support the findings of the study can be obtained from the corresponding author upon request.

\section{Conflicts of Interest}

The authors declare that there are no conflicts of interest regarding the publication of this paper.

\section{References}

[1] A. Mansouriyan, H. Ghanavatian, and M. S. Monajem, "Three dimensional analyzed of stopping sight distance for combination horizontal curve with vertical curve simulated by spline function," in Proceeding of the 13th Symposium on Transportation and Traffic, Tehran, iran, february 2014.

[2] American Association of State Highway and Transportation Officials, A Policy on Geometric Design of Highways and Streets, AASHTO, Washington, DC, USA, 2011.

[3] G. Jovanović and R. Atelšek, "Study of a highly effective and affordable highway interchange-ITL interchange," Civil Engineering Journal, vol. 6, no. 4, 2020.

[4] D. B. Fambro, J. C. Collings, R. L. Vrdova, J. P. Leisch, and J. M. Mason, Geometric Design: Past, Present and Future, Transportation Research Board, Washington, DC, US, 2008.

[5] M. Castro, L. Iglesias, J. A. Sánchez, and L. Ambrosio, "Sight distance analysis of highways using GIS tools," Transportation Research Part C: Emerging Technologies, vol. 19, no. 6, pp. 997-1005, 2011.

[6] M. L. Miller, "Analysis of viewshed accuracy with variable resolution LIDAR digital surface models and photogrammetrically derived digital elevation models," Master Thesis, Faculty of the Virginia Polytechnic Institute and State University, Blacksburg, Virginia, 2011.

[7] S. Shadpoor, A. Pirouzi, H. Hamze, and D. Mazaheri, "Determination of Bodenstein number and axial dispersion of a triangular external loop airlift reactor," Chemical Engineering Research and Design, vol. 165, pp. 61-68, 2021.

[8] Y. Hassan, S. M. Easa, and A. B. Halim, "Design considerations for combing highway alignments," Journal of Transportation Engineering, vol. 123, 1997.

[9] A. J. Khattak and H. Shamayleh, "Highway safety assessment through geographic information system-based data visualization," Journal of Computing in Civil Engineering, vol. 19, no. 4, pp. 407-411, 2005.

[10] D. G. Kim and D. J. Lovell, "A procedure for 3-D sight distance evaluation using thin plate splines," in Proceedings of the 4th International Symposium on Highway Geometric Design, Valencia, Spain, June 2010. 
[11] A. T. M. Chou, V. Pérez, A. García, and M. A. R. Rojas, "Optimal 3D coordination to maximaise the available stopping sight distance in two-lane roads," in Proceedings of the 4th International Symposium on Highway Geometric Design, Valencia, Spain, June 2010.

[12] M. Fotis and J. H. Viviana, "Model for sight distance calculation and three-dimensional alignment evaluation in divided and undivided highways," in Proceedings of the $3 \mathrm{rd}$ International Conference on Road Safety and Simulation, Indianapolis, USA, September 2011.

[13] D. S. Barbel, M. CastroL, and I. Martínez, "Sight distance for road safety analysis using GIS," in Proceedings of the Esri Europe, Middle East and Africa User Conference, Munich, Germany, October 2013.

[14] M. Castro, J. A. Anta, L. Iglesias, and J. A. Sánchez, "GIS-based system for sight distance analysis of highways," Journal of Computing in Civil Engineering, vol. 28, 2013.

[15] M. Castro, L. Iglesias, R. Rodríguez-Solano, and J. A. Sánchez, "A methodology to measure sight-hidden dips' parameters," Measurement, vol. 52, pp. 85-93, 2014.

[16] J. Dilling, "Driving behavior of motor vehicles on winding roads. research report," Strassenbau Und Strassenverkehrstechnik, Vol. 151, Bonn-Bad Godesberg, Germany, 1973.

[17] R. Lamm, Fahrdynamik und Streckencharakteristik: Ein Beitrag Zum Entwurf Von Strassen Unter Besonderer Beruecksichtigung Der Geschwindigkeit, Vol. 11, Publications of Institute of Highway and Railway Engineering of the University of Karlsruhe, Karlsruhe, Germany, 1973.

[18] G. Koeppel and H. B. Fahrgeschwindigkeiten, Abhaengigkeit von der Kurvigkeit. Research Report, Strassenbau und StrassenverkehrstechnikVol. 269, Bonn-Bad Godesberg, Germany, 1979.

[19] R. Lamm, E. M. Choueiri, J. C. Hayward, and A. Paluri, Possible Design Procedure to Promote Design Consistency in Highway Geometric Design on Two-Lane Rural Road$s$ Transportation Research Record 1195, TRB, National Research Council, Washington, DC, USA, 1988.

[20] R. Lamm, E. M. Choueiri, and T. Mailaender, Comparison of Operating Speeds on Dry and Wet Pavements of Two-Lane Rural HighwaysTransportation Research Record 1280, TRB, National Research Council, Washington, DC, USA, 1990.

[21] J. Morrall and R. J. Talarico, "Side friction demanded and margins of safety on horizontal curves," in Transportation Research Record 1435, TRB, pp. 145-152, National Research Council, Washington, DC, USA, 1994.

[22] M. N. Islam and P. N. Seneviratne, "Evaluation of design consistency of two-lane rural highways," ITEA Journal, vol. 64, no. 2, pp. 28-31, 1994.

[23] R. A. Krammes, Q. Brackett, M. A. Shafer et al., Horizontal Alignment Design Consistency for Rural Two-Lane Highways. Report No. FHWA-RD-94-034, Federal Highway Administration, U.S. Department of Transportation, Washington, DC, US, 1995.

[24] A. P. Voigt and R. A. Krammes, An Operational and Safety Evaluation of Alternative Horizontal Curve Design Approaches on Rural Two-Lane Highways, Texas Transportation Institute Research, College Station, 1996.

[25] C. Lippold, Weiterentwicklung ausgewaehlter Entwurfsgrundlagen von Landstrassen, Ph.D. Dissertation, Technical University of Darmstadt, Germany, 1997.

[26] K. A. Passetti and D. B. Fambro, "Operating speeds on curves with and without spiral transitions," Transportation Research Record: Journal of the Transportation Research Board, vol. 1658, no. 1, pp. 9-16, 1999.
[27] J. McFadden and L. Elefteriadou, "Evaluating horizontal alignment design consistency of two-lane rural highways: development of new procedure," Transportation Research Record: Journal of the Transportation Research Board, vol. 1737, no. 1, pp. 9-17, 2000.

[28] K. L. Fitzpatrick, L. Elefteriadou, D. Harwood et al., Speed Prediction for Two-Lane Rural Highways. Report FHWA-RD99-171. Federal Highway Administration, U.S. Department of Transportation, Washington, DC, US, 2000b.

[29] D. R. Jessen, K. S. Schurr, P. T. McCoy, G. Pesti, and R. R. Huff, "Operating speed prediction on crest vertical curves of rural two-lane highways in Nebraska," Transportation Research Record: Journal of the Transportation Research Board, vol. 1751, no. 1, pp. 67-75, 2001.

[30] B. Nie and Y. Hassan, "Modeling driver speed behavior on horizontal curves of different road Classifications," in Proceedings of the Presented at 86th Annual Meeting of the Transportation Research Board, Washington, DC, USA, January 2007.

[31] S. Cafiso, A. Di Graziano, G. Di Silvestro, and G. La Cava, "Safety performance indicators for local rural roads: a comprehensive procedure from low-cost data survey to accident prediction model," in Proceedings of the Presented at the 87th Annual Meeting of the Transportation Research Board, Washington, DC, USA, January 2008. 